\title{
$\mathrm{KJCCM}$
}

\section{Malignant Syndrome in Parkinson Disease Similar to Severe Infection}

\author{
Dong Hun Lee, Jeong Mi Moon, and Yong Soo Cho
}

Department of Emergency Medicine, Chonnam University Hospital, Chonnam National University Medical School, Gwangju, Korea

\begin{abstract}
A 70-year-old woman with Parkinson disease was admitted to the emergency department with altered consciousness, fever and convulsive movements without experiencing withdrawal from antiparkinsonian medication. Six hours after the emergency department visit, the patient had a hyperpyrexia $\left(>40^{\circ} \mathrm{C}\right)$ and a systolic blood pressure of $40 \mathrm{mmHg}$. There was no evidence of bacterial infection based on extensive workups. The patient was discharged without aggravation of Parkinson disease symptoms after treatment that included administration of dantrolene sodium, enforcement of continuous renal replacement therapy and cooling blankets. Malignant syndrome should be suspected if high fever occurs in Parkinson disease patients without evidence of a definitive infection.
\end{abstract}

Key Words: dehydration; fever; malignant syndrome; Parkinson disease.

Malignant syndrome (MS) in Parkinson disease (PD) is rare but potentially fatal. Takubo et al. [1] reported that MS in PD who did not recover to the pre-MS state was 33\%. Clinical features of MS in PD include muscle rigidity, hyperpyrexia, and altered consciousness, which are similar to the clinical symptoms of neuroleptic MS [1-3]. Neuroleptic MS has been reported in patients receiving neuroleptic drugs, whereas MS in PD has been reported in patients following withdrawal of antiparkinsonian drugs [1,2]. If MS in PD is not caused by withdrawal of antiparkinsonian drugs, the typical symptoms of MS in PD, such as fever and autonomic instability, are difficult to distinguish from systemic inflammatory response syndrome (SIRS), resulting in delayed diagnosis and treatment. We present a case of an elderly woman who was initially misdiagnosed with SIRS instead of MS because of no history of withdrawal of antiparkinsonian drugs.

\section{Case Report}

A 70-year-old woman with a 9-year history of PD was admitted to the emergency department (ED) with a 1-day history of altered consciousness, fever, and convulsive movements. She was already bedridden (Hoehn and Yahr scale 5) and had left hand tremor. Her medications included carbidopa/levodopa (25 mg/100 mg per oral [PO] three times a day) and memantine (10 mg PO twice a day). Her family member informed us that she had taken her antiparkinsonian medi-

\footnotetext{
Received on February 16, 2016 Revised on June 2, 2016 Accepted on August 12, 2016 Correspondence to: Jeong Mi Moon, Department of Emergency Medicine, Chonnam University Hospital, Chonnam National University Medical School, 42 Jebong-ro, Dong-gu, Gwangju 61469, Korea

Tel: +82-62-220-6809, Fax: +82-62-228-7417, E-mail: emdrmim@gmail.com

*No potential conflict of interest relevant to this article was reported.
}

cc This is an Open Access article distributed under the terms of the Creative Commons Attribution Non-Commercial License (http://creativecommons.org/ licenses/by-nc/4.0/) which permits unrestricted non-commercial use, distribution, and reproduction in any medium, provided the original work is properly cited. Copyright (c) 2017 The Korean Society of Critical Care Medicine 
cations regularly before admission to the ED and that she had recurrent diarrhea with poor oral intake 1 week before the ED visit. After the recurrent diarrhea 1 week before the ED visit, the left hand tremor was aggravated. At admission, her vital signs included a blood pressure of $100 / 60 \mathrm{mmHg}$, temperature of $39.0^{\circ} \mathrm{C}$, respiratory rate of 24 breaths/min, and heart rate of 138 beats $/ \mathrm{min}$. A physical examination showed hot and wet skin, rigidity of extremities, and left hand tremor. The patient showed seizure-like movements accompanied by left-sided eye deviation and muscle contraction 30 minutes after admission to the ED. The results of an arterial blood gas analysis showed respiratory alkalosis $\left(\mathrm{pH} 7.51, \mathrm{PaCO}_{2} 22 \mathrm{mmHg}, \mathrm{PaO}_{2} 148\right.$ $\mathrm{mmHg}$, and $\mathrm{HCO}_{3}{ }^{-} 18.3 \mathrm{mEq} / \mathrm{L}$ ) via $\mathrm{O}_{2}$ face mask $10 \mathrm{~L}$. The initial laboratory results showed a white blood cell count of $16.2 \times 10^{3} / \mathrm{L}$, sodium at $146 \mathrm{mEq} / \mathrm{L}$, blood urea nitrogen $(\mathrm{BUN})$ at $34.4 \mathrm{mg} / \mathrm{dl}$, creatinine at $0.6 \mathrm{mg} / \mathrm{dl}$, creatinine kinase $(\mathrm{CK})$ at $41 \mathrm{U} / \mathrm{L}$, and $\mathrm{C}$-reactive protein $(\mathrm{CRP})<0.5 \mathrm{mg} / \mathrm{dl}$. The computed tomography (CT) scan of the chest and abdomen did not show any abnormal findings. The brain CT showed severe brain atrophy with communicating hydrocephalus, but the cerebrospinal fluid examination result was normal. An electroencephalogram showed no epileptiform abnormalities. There were no cultured bacteria in the patient's blood or urine. Six hours after admission, the patient showed high fever $\left(>40^{\circ} \mathrm{C}\right)$. The blood pressure of this patient was $90 / 50$

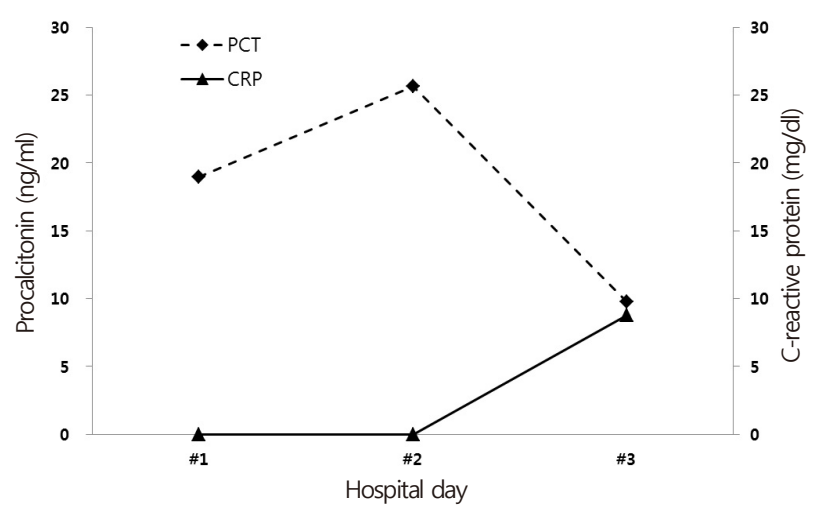

Figure 1. Change in procalcitonin (PCT) and C-reactive protein (CRP) during the first 3 days. At admission, the level of PCT was extremely high (reference range, $0-0.5 \mathrm{ng} / \mathrm{ml}$ ), while the level of CRP was within the normal range (reference range, $0.1-1 \mathrm{mg} / \mathrm{dl}$ ). $\mathrm{mm} / \mathrm{Hg}$ despite administering $1.5 \mathrm{~L}$ of $0.9 \% \mathrm{NaCl}$ over 4 hours. At 12 hours after admission, blood pressure was decreased (systolic blood pressure of $40 \mathrm{mmHg}$ ) and her respiration was shallow. Then, we decided intubation and mechanical ventilation support, and the patient was given a vasopressor (norepinephrine $0.6 \mu \mathrm{g} / \mathrm{kg} / \mathrm{h}$ IV). Central venous catheterization was performed via the right subclavian vein and central venous pressure was $3 \mathrm{mmHg}$. To control the fever, dantrolene sodium (40 mg IV) and a cooling blanket were used; as a result, her temperature decreased to $36^{\circ} \mathrm{C} 15$ hours after admission. At 14 hours after admission, the laboratory results indicated sodium at $149 \mathrm{mEq} / \mathrm{L}, \mathrm{BUN}$ at $63.3 \mathrm{mg} / \mathrm{dl}$, creatinine at $1.6 \mathrm{mg} / \mathrm{dl}$, serum procalcitonin (PCT) at $25.63 \mathrm{ng} / \mathrm{ml}$, and myoglobin at $970.8 \mathrm{ng} / \mathrm{ml}$ but showed no elevated CRP (Figure 1). Based on a presumptive diagnosis of severe pseudomembranous colitis due to a history of antibiotic use (ceftriaxone $2 \mathrm{~g}$ for 5 days) 1 month before and elevated PCT, oral vancomycin was given once. Urine output was decreased $(<0.4 \mathrm{ml} / \mathrm{kg} / \mathrm{h})$, and hence, continuous venovenous hemodiafiltration (CVVHDF) with multiFiltrate (Fresenius Medical Care, Bad Homburg, Germany) for acute kidney injury and oligouria was applied at 20 hours after admission. At 43 hours after admission, the laboratory results showed elevated CK (274 U/L) and decreased PCT levels (9.79 ng/ $\mathrm{ml})$. Clostridium difficile and its toxins were not detected in the stool and results of polymerase chain reaction assays were negative. There was improvement in the renal function tests and oligouria, so CVVHDF was stopped at 56 hours after admission. Based on a diagnosis of MS in $\mathrm{PD}$ on the 4th hospital day (HD), the patient received antiparkinsonian drugs that had been taken previously via a Levin tube. The frequency of the left hand tremor decreased, and her consciousness recovered to its previous condition. Weaning and extubation were performed on the 12th HD. After conservative treatment, she was discharged on the 22nd HD after recovery to her previous condition before admission. 


\section{Discussion}

In our case, the patient was diagnosed with MS based on the modified diagnostic criteria of Levenson $[1,3]$. Our patient showed delayed mild elevation of CK, but this could be explained by focal subclinical rhabdomyolysis or due to an increase in the permeability of the muscle membrane [2]. Myoglobinemia may also serve as an evidence of rhabdomyolysis.

The most common cause of MS in PD is withdrawal from antiparkinsonian drugs $(29 \%)$, followed by infection (19\%), and poor oral intake (13\%) [1]. Additionally, sodium imbalance can cause MS in PD [4-6]. The dehydration caused by persistent diarrhea and hypernatremia may have been the cause of MS in our patient. Old age, high Hoehn and Yahr stage during the symptomatic phase of MS, high akinesia score, and an absence of withdrawal symptoms from medication prior to developing MS have been associated with poor outcomes [1]. In our case, the patient had a high Hoehn and Yahrscore, high akinesia score, and no withdrawal symptoms from dopaminergic medication. Furthermore, as it was difficult to distinguish between MS and SIRS, the diagnosis of MS in PD was delayed. Therefore, our patient was expected to have a poor outcome. However, she recovered to her previous condition, perhaps because her high fever was quickly corrected by dantrolene sodium and cooling blankets. One previous study found that the outcome of malignant hyperthermia depends on the time interval from the start of the reaction to the establishment of correct treatment, which includes terminating the trigger agent exposure and administering dantrolene [7]. Therefore, this intensive therapy reduced the duration of MS and helped the recovery of our patient.

This patient showed high serum PCT levels at an early stage, but at that time, we found no evidence of severe infection; serum PCT levels may also be elevated by non-infectious causes, such as inhalation injury, burn injury, mechanical trauma, extensive surgery, or heatstroke tissue injury [8]. Because PCT can be produced by tissue injury, we think that hyperpyrexia and rhabdomyolysis of
MS in PD may cause damage to muscle tissue, resulting in elevated PCT. Lovas et al. [9] reported that a young male patient presenting with high fever and neurological impairment caused by amphetamine intoxication showed extremely high serum PCT levels without evidence of a bacterial infection. Because serum PCT decreases daily by approximately $50 \%$ due to its half-life, high serum PCT levels may not be associated with a bacterial infection. However, a follow-up blood culture showed methicillin-resistant Staphylococcus aureus, which was considered to be a catheter related infection for CVVHDF.

In summary, emergency physicians should consider MS in patients who have a history of PD and who present with high fever without evidence of an infection. Additionally, physicians should know that PCT in patients with MS can be elevated without a concomitant bacterial infection.

\section{ORCID}

Dong Hun Lee http://orcid.org/0000-0003-3612-3443

Jeong Mi Moon http://orcid.org/0000-0002-9182-5475

Yong Soo Cho http://orcid.org/0000-0001-8306-2298

\section{References}

1. Takubo H, Harada T, Hashimoto T, Inaba Y, Kanazawa I, Kuno S, et al. A collaborative study on the malignant syndrome in Parkinson disease and related disorders. Parkinsonism Relat Disord 2003;9 Suppl $1: \mathrm{S} 31-41$

2. Levenson JL. Neuroleptic malignant syndrome. Am J Psychiatry 1985;142:1137-45.

3. Mizuno Y, Takubo H, Mizuta E, Kuno S. Malignant syndrome in Parkinson disease: concept and review of the literature. Parkinsonism Relat Disord 2003;9 Suppl 1:S3-9.

4. Chandran CJ. Malignant syndrome in Parkinson disease without dopaminergic drug withdrawal. Ann 
Indian Acad Neurol 2008;11:248-50.

5. Sechi G, Manca S, Deiana GA, Corda DG, Pisu A, Rosati G. Acute hyponatremia and neuroleptic malignant syndrome in Parkinson disease. Prog Neuropsychopharmacol Biol Psychiatry 1996;20:533-42.

6. Cao L, Latz RH. Acute hypernatremia and neuroleptic malignant syndrome in Parkinson disease. Am J Med Sci 1999;318:67-8.

7. Broman M, Islander G, Müller CR. Malignant hyperthermia, a Scandinavian update. Acta Anaesthesiol
Scand 2015;59:951-61.

8. Becker KL, Snider R, Nylen ES. Procalcitonin assay in systemic inflammation, infection, and sepsis: clinical utility and limitations. Crit Care Med 2008;36:941-52.

9. Lovas A, Agoston Z, Késmárky K, Hankovszky P, Molnár Z. Extreme procalcitonin elevation without proven bacterial infection related to amphetamine abuse. Case Rep Crit Care 2014;2014:179313. 